\begin{tabular}{|c|c|c|}
\hline $\begin{array}{l}\text { INESEG } \\
\text { INTERNATIONAL } \\
\text { ENGINEERING } \\
\text { SCIENCE AND } \\
\text { EDUCATIONGROUP }\end{array}$ & $\begin{array}{c}\text { International Journal of Health Services } \\
\text { Research and Policy } \\
\text { www.dergipark.org.tr/ijhsrp } \\
\text { e-ISSN: } 2602-3482\end{array}$ & IJHSRP \\
\hline
\end{tabular}

Research Article

\title{
FREQUENCY OF DAYTIME SLEEPINESS OF FACTORY WORKERS WORKING IN SHIFTS AND ITS EFFECT ON ANXIETY
}

\author{
Sanidin Kantar $^{\text {(D) Rabia Sohbet }}{ }^{2}$ (i) Fatma Karasu ${ }^{3}$ (D) Canan Birimoglu Okuyan 4 (D) \\ ${ }^{1}$ Department of Public Health Nursing, Gaziantep University, Turkey \\ ${ }^{2}$ Department of Public Health Nursing, Gaziantep University, Turkey \\ ${ }^{3}$ Department of Public Health Nursing, Kilis 7 Aralık University, Turkey \\ ${ }^{4}$ Department of Public Health Nursing, Sakarya University of Applied Science \\ *Corresponding Author;rasohbet@yahoo.com
}

\begin{abstract}
This descriptive and cross-sectional study was conducted to examine the frequency of daytime sleepiness and its effects on anxiety in factory workers working in shifts. The population of the research consisted of 1052 workers working in two factories. The data were collected using the data collection form, the Epworth Sleepiness Scale, and the Beck Anxiety Inventory. Normally distributed data were presented as number, percentage, mean, and standard deviation. Independent samples t-test and ANOVA were used in statistical analysis. The mean Epworth Sleepiness Scale score of shift workers was $10.4 \pm 4.2$ and $42.8 \%$ had excessive daytime sleepiness. When the Epworth Sleepiness Scale scores and Beck Anxiety Inventory scores of the workers participating in the research were compared, it was determined that the daytime sleepiness levels of shift workers increased as anxiety risk increased, and the effect on vital characteristics was statistically significant $(P$ $<0.05)$. Therefore, interventions, effective coping methods, and training strategies should be developed in order to improve the sleep quality, especially daytime sleep quality, and vital characteristics of shift workers.
\end{abstract}

Keywords: Occupational health, Workers, Working in shifts, Sleep disorder

Received: April 17, 2020

Accepted: September 2, 2020

\section{Introduction}

The work comprising recurring periods where different groups of workers do the same jobs in the relay is called shift work [1]. Shift work accounts for about $20 \%$ of the labor force in industrial countries [2], and shift conditions can often cause low sleep quality and excessive sleepiness in workers [3].

Shift times can be fixed or rotating, but are often variable, irregular, and formed according to the needs [4]. Generally, shift work is defined as a non-traditional work type that changes over a 24 hour period and between 6:00 am and 6:00 pm [5]. Previous studies have shown that shift working conditions, especially night shifts, may affect the health of the employees negatively [6]. The health problems in shift working are often closely related to psychological problems, sleep disorders, diabetes mellitus, 
metabolic syndrome, obesity, heart disease, and cancer [6-11]. Furthermore, one of the crucial reasons for the differences in health between standard workers and shift workers is sleep problems [11, 12].

Considering that adult individuals need to sleep for an average of 7-8 hours [13], getting enough sleep is critical for an individual's mental and physical health. Also, individuals working under shift conditions may experience conflict and problems in their relations with their families as a result of not being able to spend enough time with their families. However, this could be handled by family support, social support, and a better working environment [14]. Sleep disorders and relationship problems with families due to shifting work is one of the most important problems of modern society and working life. Therefore, this study was conducted to examine the frequency of excessive daytime sleepiness among factory workers working in shifts and its effects on anxiety and to raise awareness among workers on this issue.

\section{Research Questions}

1. What is the daytime sleepiness level of shift factory workers?

2. Does daytime sleepiness affect the anxiety of shift factory workers?

\section{Material and Methods}

\subsection{Study Design}

This study was a descriptive and cross-sectional study.

\subsection{Population and Sample}

The population of the research consists of workers working in two factories (a total of 1475 factory workers). However, a simple random sampling method was used to reach 1052 volunteers.

The inclusion criteria set by the researchers:

(1) Aged 18 years or older;

(2) Able to read in the Turkish language;

(3) The workers who in Gaziantep where is the South of Turkey;

(4) Full-time working and at least have 1-year working experience in the factory;

(5) Working in a shift.

\subsection{Data Collection Tools}

Data were collected between 07-12.2016. In the first part of the data collection form developed by the researchers $[3,8,9,11]$. There are 25 questions on demographics and some vital characteristics of the participants. In the second part, the Epworth Sleepiness Scale and the Beck Anxiety Inventory were used to determine the sleepiness levels of the participants.

\subsubsection{Epworth Sleepiness Scale (ESS)}

The scale developed by Johns (1991) is a test used to demonstrate daytime sleepiness [15]. The validity and reliability of the scale were conducted by Agargun et al in Turkish society [16]. The possibility of falling asleep in certain situations on an ordinary day is questioned. It consists of 8 questions and the questions are scored between 0 and 3 points. The total score ranges from 0 to 24 . A score of $\geq 10$ indicates excessive daytime sleepiness [15]. In our study group, the reliability of the scale was tested and Cronbach's alpha coefficient was found to be 0.74 . 


\subsubsection{Beck Anxiety Inventory (BAI)}

It was developed by Beck in 1988 [17]. The validity and reliability of the scale were conducted by Ulusoy et al in Turkish society [18]. The scale aims to determine the frequency and severity of the anxiety symptoms experienced by individuals. It consists of 21 items and is a Likert type scale. Each item is scored between 0 and 3. A score of 0-7 points is considered as no anxiety, 8-15 points are considered as mild anxiety, 16-25 points is considered as moderate anxiety, and 26-63 points is considered as severe anxiety. The scale measures the frequency of anxiety symptoms experienced by the individual. For this study, Cronbach's alpha coefficient was calculated as 0.92 .

\subsection{Data Analysis}

Statistical Package for Social Sciences (SPSS) 22.0 software was used for statistical analyses. Kolmogorov-Smirnov distribution test was used to examine the normal distribution of variables. Descriptive statistical methods (frequency, percentage, mean, and standard deviation) were used to evaluate the research data, and the t-test and ANOVA tests were used for group comparisons in independent groups.

\section{Ethical Considerations}

The Clinical Research Ethics Committee approved the study of Gaziantep University (Decision's date and number: 2016/172) and institutional permission was obtained for this study. Before starting the study, the aim of the research was explained to the workers by the researcher and verbal consent was obtained. Questionnaires were filled in 10-15 minutes by face-to-face interviews.

\section{Results}

The mean age of the participants was $32.3 \pm 6.8$. Table 1 shows the comparison of sociodemographic characteristics and means the Epworth Sleepiness Scale scores of the participants. When the mean ESS scores of shift workers were compared with respect to age, gender, marital status, and educational status, it was found that the difference was not statistically significant $(\mathrm{P}>0.05)$. When the mean ESS scores of the workers were compared in terms of smoking, alcohol use, duration of employment, weekly working hours, shift type, overtime status, presence of occupational disease, and previous occupational accident, the difference was found to be statistically significant $(\mathrm{P}<0.05)$ (Table 1$)$. 
Table 1. Comparison of Socio-Demographic Characteristics and Mean Epworth Sleepiness Scale Scores of Shift Workers $(\mathrm{N}=1052)$

\begin{tabular}{|c|c|c|c|c|}
\hline & \multirow[b]{2}{*}{ Number } & \multirow[b]{2}{*}{$\%$} & \multicolumn{2}{|c|}{ Epworth Sleepiness Scale } \\
\hline & & & $\mathrm{X} \pm \mathrm{SD}$ & Significance \\
\hline \multicolumn{5}{|l|}{ Age } \\
\hline $18-30$ years & 463 & 44.0 & $8.9 \pm 3.9$ & \multirow{3}{*}{$\begin{array}{c}* \mathrm{~F}=1.559 \\
\mathrm{p}=0.211\end{array}$} \\
\hline $31-40$ years & 461 & 43.8 & $9.0 \pm 3.6$ & \\
\hline $41 \geq$ years & 128 & 12.2 & $9.6 \pm 4.8$ & \\
\hline \multicolumn{5}{|l|}{ Gender } \\
\hline Male & 876 & 83.3 & $9.0 \pm 3.8$ & \multirow{2}{*}{$\begin{array}{c}* \mathrm{t}=-0.087 \\
\mathrm{p}=0.931\end{array}$} \\
\hline Female & 176 & 16.7 & $9.0 \pm 4.3$ & \\
\hline \multicolumn{5}{|l|}{ Marital Status } \\
\hline Married & 838 & 79.7 & $9.1 \pm 3.7$ & \multirow{2}{*}{$\begin{array}{l}\mathrm{t}=1.024 \\
\mathrm{p}=0.306\end{array}$} \\
\hline Single & 214 & 20.3 & $8.7 \pm 4.5$ & \\
\hline \multicolumn{5}{|l|}{ Educational Status } \\
\hline Illiterate & 19 & 1.8 & $9.4 \pm 4.7$ & \multirow{3}{*}{$\begin{array}{l}F=0.880 \\
p=0.415\end{array}$} \\
\hline Primary School & 472 & 44.9 & $9.2 \pm 4.3$ & \\
\hline High School or above & 561 & 53.3 & $8.8 \pm 3.5$ & \\
\hline \multicolumn{5}{|l|}{ Smoking } \\
\hline Smoker & 540 & 51.3 & $9.3 \pm 3.7$ & \multirow{2}{*}{$\begin{array}{l}t=2.801 \\
\mathbf{p}=\mathbf{0 . 0 0 5}\end{array}$} \\
\hline Non-Smoker & 512 & 48.7 & $8.6 \pm 4.1$ & \\
\hline \multicolumn{5}{|l|}{ Alcohol Use } \\
\hline Yes & 138 & 13.1 & $10.1 \pm 4.8$ & \multirow{2}{*}{$\begin{array}{l}\mathrm{t}=3.689 \\
\mathbf{p}=\mathbf{0 . 0 0 1}\end{array}$} \\
\hline No & 914 & 86.9 & $8.8 \pm 3.7$ & \\
\hline \multicolumn{5}{|c|}{ Duration of Employment } \\
\hline$\leq 10$ years & 674 & 64.1 & $8.7 \pm 4.0$ & \multirow{3}{*}{$\begin{array}{l}F=7.745 \\
p=\mathbf{0 . 0 0 1}\end{array}$} \\
\hline $11-20$ years & 309 & 29.4 & $9.4 \pm 3.4$ & \\
\hline$\geq 21$ years & 69 & 6.6 & $10.3 \pm 4.0$ & \\
\hline \multicolumn{5}{|l|}{ Weekly work hours } \\
\hline 48 hours & 753 & 71.6 & $8.7 \pm 3.5$ & \multirow{2}{*}{$\begin{array}{l}\mathrm{t}=-4.361 \\
\mathbf{p}=\mathbf{0 . 0 0 1}\end{array}$} \\
\hline$\geq 48$ hours & 299 & 28.4 & $9.8 \pm 4.5$ & \\
\hline \multicolumn{5}{|l|}{ Shift Type } \\
\hline Day shift only & 167 & 15.9 & $7.1 \pm 3.1$ & \multirow{3}{*}{$\begin{array}{l}F=5.442 \\
\mathbf{p}=\mathbf{0 . 0 2 8}\end{array}$} \\
\hline Night shift only & 76 & 7.2 & $9.7 \pm 5.1$ & \\
\hline Rotational shift & 809 & 76.9 & $9.1 \pm 3.7$ & \\
\hline \multicolumn{5}{|l|}{ Overtime (Monthly) } \\
\hline No overtime & 170 & 16.2 & $7.5 \pm 4.4$ & \multirow{4}{*}{$\begin{array}{c}F=15.436 \\
\mathbf{p}=\mathbf{0 . 0 0 1}\end{array}$} \\
\hline 1-16 hours & 379 & 36.0 & $8.5 \pm 3.5$ & \\
\hline 17-32 hours & 306 & 29.1 & $8.9 \pm 4.2$ & \\
\hline$\geq 33$ hours & 197 & 18.7 & $9.9 \pm 3.5$ & \\
\hline \multicolumn{5}{|c|}{ Presence of occupational disease } \\
\hline Yes & 111 & 10.6 & $10.8 \pm 4.5$ & $\mathrm{t}=5.144$ \\
\hline No & 941 & 89.4 & $8.8 \pm 3.8$ & $\mathrm{p}=\mathbf{0 . 0 0 1}$ \\
\hline Previous occupationa & & & & \\
\hline Yes* & 474 & 45.1 & $9.5 \pm 3.5$ & \\
\hline No & 578 & 54.9 & $8.6 \pm 4.1$ & $t=3.950$ \\
\hline Total & 1052 & 100.0 & & $\mathrm{p}=0.001$ \\
\hline
\end{tabular}


When mean ESS scores of the workers were compared in terms of working hours affecting regular sleep pattern, insomnia affecting health or psychology, feeling psychological burnout during working hours, having an adequate and balanced diet, thinking of having sufficient social relations, shift work affecting family order, spending enough time with children, paying attention to and helping children with their homework, going on vacation with family, and feeling burnout in communicating with family, it was found that the difference was statistically significant $(\mathrm{P}<0.05)$ (Table 2$)$.

Table 2. Comparison of Some Vital Characteristics of Shift Workers and Mean Epworth Sleepiness Scale Scores $(\mathrm{N}=1052)$

\begin{tabular}{|c|c|c|c|c|}
\hline & \multirow[b]{2}{*}{ Number } & \multirow[b]{2}{*}{$\%$} & \multicolumn{2}{|c|}{ Epworth Sleepiness Scale } \\
\hline & & & $\mathbf{X} \pm \mathbf{S D}$ & Significance \\
\hline \multicolumn{4}{|c|}{ Do your working hours affect your regular sleep pattern? } & \multirow{3}{*}{$\begin{array}{l}t=4.673 \\
\mathbf{p}=\mathbf{0 . 0 0 1}\end{array}$} \\
\hline Yes & 710 & 67.5 & $9.4 \pm 3.8$ & \\
\hline No & 342 & 32.5 & $8.2 \pm 3.9$ & \\
\hline \multicolumn{4}{|c|}{ Does insomnia affect your health or psychology? } & \multirow{3}{*}{$\begin{array}{l}t=4.107 \\
\mathbf{p}=\mathbf{0 . 0 0 1}\end{array}$} \\
\hline Yes & 753 & 71.6 & $9.3 \pm 3.8$ & \\
\hline No & 299 & 28.4 & $8.2 \pm 4.0$ & \\
\hline \multicolumn{4}{|c|}{ Do you feel psychological burnout during working hours? } & \multirow{3}{*}{$\begin{array}{l}t=4.375 \\
\mathbf{p}=\mathbf{0 . 0 0 1}\end{array}$} \\
\hline Yes & 658 & 62.5 & $9.4 \pm 3.9$ & \\
\hline No & 394 & 37.5 & $8.3 \pm 3.8$ & \\
\hline \multicolumn{4}{|c|}{ Do you think you have an adequate and balanced diet? } & \multirow{3}{*}{$\begin{array}{l}t=-1.988 \\
\mathbf{p}=\mathbf{0 . 0 4 7}\end{array}$} \\
\hline Yes & 265 & 25.2 & $8.6 \pm 4.1$ & \\
\hline No & 787 & 74.8 & $9.1 \pm 3.8$ & \\
\hline \multicolumn{4}{|c|}{ Do you pay enough attention to daily tasks and chores? } & \multirow{3}{*}{$\begin{array}{l}\mathrm{t}=-0.667 \\
\mathrm{p}=0.500\end{array}$} \\
\hline Yes & 243 & 23.1 & $8.8 \pm 3.9$ & \\
\hline No & 809 & 76.9 & $9.0 \pm 3.9$ & \\
\hline \multicolumn{4}{|c|}{ Do you think your social relations are sufficient? } & \multirow{3}{*}{$\begin{array}{l}t=-3.347 \\
\mathbf{p}=\mathbf{0 . 0 0 1}\end{array}$} \\
\hline Yes & 380 & 36.1 & $8.5 \pm 3.7$ & \\
\hline No & 672 & 63.9 & $9.3 \pm 4.0$ & \\
\hline \multicolumn{4}{|c|}{ Does your family want you to work on the night shift? } & \multirow{3}{*}{$\begin{array}{l}\mathrm{t}=-1.760 \\
\mathrm{p}=0.079\end{array}$} \\
\hline Yes & 200 & 19.0 & $8.6 \pm 3.9$ & \\
\hline No & 852 & 81.0 & $9.1 \pm 3.9$ & \\
\hline \multicolumn{4}{|c|}{ Does shift work affect your family order? } & \multirow{3}{*}{$\begin{array}{l}t=2.681 \\
\mathbf{p}=\mathbf{0 . 0 0 7}\end{array}$} \\
\hline Yes & 726 & 69.0 & $9.2 \pm 3.7$ & \\
\hline No & 326 & 31.0 & $8.5 \pm 4.2$ & \\
\hline \multicolumn{4}{|c|}{ Can you spare enough time for your wife? } & \multirow{3}{*}{$\begin{array}{l}t=0.309 \\
p=0.751\end{array}$} \\
\hline Yes & 313 & 29.8 & $9.0 \pm 3.7$ & \\
\hline No & 739 & 70.2 & $9.3 \pm 4.2$ & \\
\hline \multicolumn{4}{|c|}{ Can you spend enough time with your children? } & \multirow{3}{*}{$\begin{array}{l}t=-3.071 \\
\mathbf{p}=\mathbf{0 . 0 0 2}\end{array}$} \\
\hline Yes & 319 & 30.3 & $8.4 \pm 3.7$ & \\
\hline No & 733 & 69.7 & $9.2 \pm 3.9$ & \\
\hline \multicolumn{4}{|c|}{ Can you help your children with their school work? } & \multirow{3}{*}{$\begin{array}{l}t=-2.331 \\
\mathbf{p}=\mathbf{0 . 0 2 0}\end{array}$} \\
\hline Yes & 242 & 23.0 & $8.5 \pm 4.0$ & \\
\hline No & 810 & 77.0 & $9.1 \pm 3.8$ & \\
\hline \multicolumn{4}{|c|}{ Do you go on vacation with your family? } & \\
\hline Yes & 291 & 27.7 & $8.2 \pm 3.5$ & 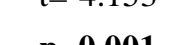 \\
\hline No & 761 & 72.3 & $9.3 \pm 4.0$ & $\mathbf{p}=\mathbf{0 . 0 0 1}$ \\
\hline Do y & cating wit & amily? & & $t=-6.185$ \\
\hline Yes & 899 & 85.5 & $8.7 \pm 3.9$ & $t=-0.10 \mathrm{~J}$ \\
\hline No & 153 & 14.5 & $10.8 \pm 3.1$ & $\mathrm{p}=\mathbf{0 . 0 0 1}$ \\
\hline
\end{tabular}

*t=Independent-Samples t-test 
When the mean ESS scores and mean BAI scores of the workers participating in our study were compared, it was found that daytime sleepiness levels of shift workers increased as anxiety risk increased, and the difference was statistically significant $(\mathrm{P}<0.05)$ (Table 3).

Table 3. Comparison of Epworth Sleepiness Scale and Beck Anxiety Inventory Scores of Shift Workers $(\mathrm{N}=1052)$

\begin{tabular}{|c|c|c|c|}
\hline & \multicolumn{3}{|c|}{$\begin{array}{l}\text { Mean Beck Anxiety Inventory } \\
\text { Score }\end{array}$} \\
\hline & N, \% & $\mathbf{X} \pm \mathbf{S D}$ & Significance \\
\hline & & $18.1 \pm 7.9$ & \\
\hline \multicolumn{4}{|c|}{ Epworth Sleepiness Scale (0-24) } \\
\hline $10<$ points & $602(57.2)$ & $15.1 \pm 6.8$ & \multirow{2}{*}{$\begin{array}{c}F=146.245 \\
\mathbf{p}=\mathbf{0 . 0 0 1}\end{array}$} \\
\hline $10 \geq$ points & $450 \quad(42.8)$ & $24.8 \pm 9.9$ & \\
\hline & \multicolumn{3}{|c|}{ Mean Epworth Sleepiness Scale Score } \\
\hline Beck Anxiety Inv & & $10.4 \pm 4.2$ & \multirow{5}{*}{$\begin{array}{c}F=57.756 \\
\mathbf{p}=\mathbf{0 . 0 0 1}\end{array}$} \\
\hline No anxiety & $56(5.3)$ & $7.1 \pm 2.7$ & \\
\hline Mild anxiety & 249 & $7.6 \pm 3.3$ & \\
\hline Moderate anxiety & $356(33.8)$ & $8.2 \pm 3.5$ & \\
\hline Severe anxiety & $391(37.2)$ & $10.9 \pm 4.0$ & \\
\hline
\end{tabular}

There was a positive correlation between the Epworth Sleepiness Scale and the Beck Anxiety Inventory scores. It was found that the risk of anxiety increased as the daytime sleepiness level increased or the risk of anxiety decreased as the daytime sleepiness level decreased $(r=0.631, \mathrm{P}<0.05)$ (Table 4).

Table 4. The Correlation between the Epworth Sleepiness Scale and Beck Anxiety Inventory Scores of Shift Workers $(\mathrm{N}=1052)$

\begin{tabular}{llc}
\hline & & Beck Anxiety Inventory (0-63) \\
\hline Epworth Sleepiness Scale (0-24) & $\mathbf{r}$ & 0.631 \\
& $\mathbf{p}$ & $\mathbf{0 . 0 0 1}$ \\
\hline
\end{tabular}

\section{*Pearson Correlation Test}

\section{Discussion}

In recent years with rapid industrial growth and increasing demand for industrial products, businesses have switched to a shift system to make their production and service offerings continuous and efficient. Although the shift work system generally makes positive contributions to the enterprises, it can have negative effects on the employees. Shift workers experience certain problems due to irregular living conditions, which directly affects the workers and their families, and may have an indirect effect on the continuity of production and service offerings of the enterprises [14]. When the mean ESS scores of shift workers were compared in terms of age, gender, marital status, and educational level, the difference was not statistically significant $(\mathrm{P}>0.05)$ (Table 1). Ghods et al. (2017) found that there was no statistically significant difference between the mean ESS scores and age in their study on workers working in a textile factory $(\mathrm{P}>0.05)$ [19]. The results obtained in this study are consistent with the literature. 
Mean ESS scores of the participants were found to be higher in participants with a longer duration of employment, those working at night shifts only, those with $\geq 48$ work hours per week, those performing overtime, and those with previous occupational accidents (Table 1). According to a study, it was concluded that working $\geq 32$ hours a week increases the risk of injury and increase the risk of occupational accidents [20]. One of the most common problems encountered in shift work systems is a sleep disorder. It has been suggested that long-term shift work leads to chronic insomnia [21]. As in many other countries, shift hours can be changed depending on the request of the employer. The average weekly working time is 40 to 48 hours, which can be changed by the employer. Working hours may vary between occupational groups, the private sector, and government agencies. Shift work and long working hours cause serious health problems such as insomnia and fatigue as they disrupt the body rhythm [22]. The results of this study support this notion. The usual sleep period of the human body is between 23:00 and 07:00. Shift workers who are forced to work between these hours cannot fully rest during the day due to environmental factors such as daylight, traffic, and domestic noise [1]. Therefore, these people experience daytime sleepiness. Increased overtime, long years of shift work, and continuous night shifts lead to daytime sleepiness, suggesting that it can significantly increase the risk of occupational accidents. As seen in the results of this study, daytime sleepiness was found to be higher in those who had an occupational accident $(9.5 \pm 3.5)$ compared to those who did not have an occupational accident $(8.6 \pm 4.1)$ (Table 1$)$.

It was found that participants who stated that their working hours and insomnia affected their sleep patterns and health had higher mean ESS scores compared to others (Table 2). Many health problems arise as a result of distorted circadian rhythm, lifestyle change, work tension, and stress factors associated with shift work [23]. These health problems include chronic diseases such as obesity, cancer, cardiovascular disease, metabolic syndrome, and diabetes mellitus. It is thought that sleep disorder caused by the shift system forms the basis of these physical and mental disorders [24]. Irregular sleep has been reported to be a health problem seen in 3/4 of shift workers. Research indicates that shift work increases stress, decreases sleep quality, and causes health deterioration as a result of sleep disorders [25]. Workers stated that daytime sleepiness negatively affected adequate and balanced nutrition and social and family relations (Table 2). Within shift work, the most significant irregularities in nutrition and diet are observed, especially in individuals working at night [26]. Shift work increases carbohydrate consumption by changing the dietary habits of the workers and leads to irregular eating habits and a decrease in vegetable consumption. Decreased sleep due to shifts, increased wakefulness time creates more time for food consumption and leads to more food consumption than total calories that should be consumed daily [27]. In the cohort study of Lin et al., it was shown that the risk of metabolic syndrome increased approximately 3 -fold in these individuals [28]. The human body is structured to carry out daily activities during the daytime and basic activities such as sleep and rest at night. When working at night, this structure shows a change in the opposite direction. Therefore, individuals in this working system have to work at night hours. As a result of this, night work causes positive and negative effects on family and social life as well as the physiological and psychological structure of the individual. Kazemi et al. (2018) found that night shifts detached workers from social life, created problems of adaptation to social life, and these workers could not take care of their families sufficiently [29]. In particular, both men and women working in the family lead to problems in family relations [15]. Another problem is that the majority of social activities are organized for daytime workers, making socializing impossible for individuals working at night. This situation is defined as "social death" for individuals working on night 
shifts [15]. Working in the period when social life stops and having to rest in the period it starts are the source of the sociological effects of night work. Since night workers cannot spend enough time with their families during the daytime, they try to take part in social life during the daytime hours when they need to rest and end up going back to work without enough rest. This is undoubtedly the most important factor in occupational accidents that occur during night shifts [26]. The mean ESS score of shift workers is $10.4 \pm 4.2$. ESS score of $\geq 10$ indicates excessive daytime sleepiness. In this study, it was found that $42.8 \%$ (450 people) of workers experienced excessive daytime sleepiness (Table 3). In their study, Halvan1, Zare, and Mirmohammad1 (2009) found that the mean ESS score of workers with rotational watch duty was $6.9 \pm 3.6$ [24]. Wu et al. (2012) found that the mean ESS score of Chinese participants was 6.75 and $22.16 \%$ had excessive daytime sleepiness [31]. Swanson et al. (2011) found that approximately $18.0 \%$ of workers experienced excessive daytime sleepiness [32]. In this study, it is noteworthy that the mean ESS score and the ratio of workers with excessive daytime sleepiness are much higher compared to other studies. Based on these findings, and also taking into account the different requirements of sectors, it can be said that daytime sleepiness rates of the employees are also variable. The development of sleep disorder due to shift work decreases the work efficiency of the person, may cause an increase in occupational and traffic accidents, and thus may present as a serious public health problem.

It was found that anxiety risk increased as daytime sleepiness increased among the workers (Table 3) and a positive correlation was found between BAI and ESS (Table 4). These results indicate that deterioration in sleep quality increases anxiety [33]. Kalmbach et al. (2015) found a significant correlation between daytime sleepiness and anxiety [34]. In another study, a positive correlation was found between sleep quality and anxiety [35]. In the present study, the mean BAI score of the participants was found to be $18.1 \pm 7.9$, indicating moderate anxiety (Table 3). Teker and Luleci (2018) found that the mean BAI score of the workers was $8.6 \pm 9.9$ and there was a moderate correlation between daytime sleepiness level and anxiety [36]. Unlike other studies, the mean anxiety score was higher in the present study. The reasons for high anxiety levels are not only daytime sleepiness or stressful working conditions. Difficulties in family and social life, economic conditions of the country, or dismissal can also influence anxiety levels. Individuals with high anxiety levels may have a decrease in their ability to cope with stress. At the same time, there is a loss of resistance to prevent the emergence of psychological problems. It is thought that the mechanism underlying mental problems is the disruption of circadian rhythm synchronization and psychosocial stress [31]. Based on these results, the $\mathrm{H}_{1}$ hypothesis "Daytime sleepiness affects some vital characteristics in factory workers working in shifts" is accepted.

\section{Conclusion}

It was found that the deterioration in sleep quality increased anxiety and the increase in anxiety worsened sleep quality. There was a positive correlation between daytime sleepiness and anxiety.

Since shift work is common in Turkey, the majority of the population is at risk for shift work sleep disorder. Irregular working hours induce strong and rapid effects on sleep and wakefulness. The potential consequences of this circadian rhythm sleep-wakefulness disorder cover health, functionality, performance, and occupational safety as well as a social function of life. Symptoms similar to insomnia may be seen and significant health problems and economic costs due to fatigue accidents and low 
productivity may be encountered. Shifts should not be changed before five days to minimize the inconsistency between circadian rhythm and working hours is the main problem in SWSD and to facilitate adaptation to working hours. Shift changes before five days lead to insomnia, chronic sleep deprivation, and hypersomnia. For this reason, it is of great importance that workers in the shift system are selected from individuals who can adapt to this system, the shift times and change periods are arranged following the circadian rhythm, and shift-related sleep disorders are recognized early and effectively treated. Also, employees should be provided with a room where they can rest and relax before and after shifts, the rest period should be kept long, and employees suffering from sleep disorders should be identified and treated. Sleep hygiene training should be included in health improvement practices in the workplace, health promotion programs specific for sectors that can be adopted by the participants such as prevention of tobacco-alcohol use, balanced nutrition, and regular sleep pattern should be established, and further studies should be carried out.

\section{Ethical Considerations}

The Clinical Research Ethics Committee approved the study of Gaziantep University (Decision's date and number: 2016/172) and institutional permission was obtained for this study. Before starting the study, the aim of the research was explained to the workers by the researcher and verbal consent was obtained. Questionnaires were filled in 10-15 minutes by face-to-face interviews.

\section{Acknowledgment}

We would like to express our special thanks of gratitude to participants for participating in this study.

Conflict of interest: None declared.

The compliance to the Research and Publication Ethics: This study was carried out by the rules of research and publication ethics.

The study was carried out conformed to all procedures of tenets of the Declaration of Helsinki.

\section{References}

[1] Jehan, S., et al., "Shift Work and Sleep: Medical Implications and Management", Sleep medicine and disorders: international journal, 1(2), 00008, 2017.

[2] Booker, L.A., et al., "Individual vulnerability to insomnia, excessive sleepiness and shift work disorder amongst healthcare shift workers", A systematic review. Sleep Med Rev, 41, 220-233, 2018. doi: 10.1016/j.smrv.2018.03.005.

[3] Arlinghaus, A., et al., "Working Time Society consensus statements: Evidence-based effects of shift work and non-standard working hours on workers, family and community", Industrial health, 57, 184-200, 2019. doi:10.2486/indhealth.SW-4

[4] Caruso C. C., "Negative impacts of shiftwork and long work hours". Rehabil Nursing, 39, 16-25, 2014. doi:10.1002/rnj.107

[5] Arendt, J. "Shift work: Coping with the biological clock", Occup Med 60(1), 10-20, 2010. 
[6] Ferri, P., et al., "The impact of shift work on the psychological and physical health of nurses in a general hospital: a comparison between rotating night shifts and day shifts", Risk Manag Healthc Policy, 9, 203-211, 2016. doi:10.2147/RMHP.S115326

[7] Books, Candie et al. "Night Shift Work and Its Health Effects on Nurses." The health care manager 36(4), 347-353, 2017. doi:10.1097/HCM.0000000000000177

[8] Rynor, Becky. "Better sleep, better health for shift workers." CMAJ : Canadian Medical Association Journal" journal de l'Association medicale canadienne, 188, 2, E35, 2016. doi:10.1503/cmaj.109-5202

[9] Proper, K., et al. "The relationship between shift work and metabolic risk factors: A systemic review of longitudinal studies”, Am J Prev Med. 5, 147-157, 2016.

[10] Wright, K.P., et al., "Shift work and the assessment and management of shift work disorder (SWD)", Sleep Med Rev, 17, 41-54, 2013. doi: 10.1016/j.smrv.2012.02.002.

[11] Wirth, M. D., et al., "Association of shiftwork and immune cells among police officers from the Buffalo Cardio-Metabolic Occupational Police Stress Study", Chronobiology international, 34, 721-731, 2017. doi:10.1080/07420528.2017.1316732

[12] Chaput, J. P., et al., "Sleeping hours: what is the ideal number and how does age impact this?", Nature and science of sleep, 10, 421-430, 2018. doi:10.2147/NSS.S163071

[13] Johannessen, H.A., Sterud, T., "Psychosocial factors at work and sleep problems: a longitudinal study of the general working population in Norway", International of Archive Occupational Environmental Health, 90, 597-608, 2017. doi: 10.1007/s00420-017-1222-2.

[14] Kossek, E.E., et al., "Workplace social support and work-family conflıct: a meta-analysis clarıfying the influence of general and work-family-specific supervisor and organizational support", Personnel Psychology. 64, 289-313, 2011. doi: 10.1111/j.1744-6570.2011.01211.x

[15] Johns, M.W., "A new method for measuring daytime sleepiness: The Epwort Sleepiness Scale", Sleep 14, 540-545, 1991. https://doi.org/10.1093/sleep/14.6.540

[16] Agargun MY, Cilli AS, Kara H, Bilici M. "Epworth Uykululuk Ölçeği'nin geçerliği ve güvenirliği”, Turk Psikiyatri Derg ,10 (4), 261-267, 1999.

[17] Beck, A.T., et al., "An inventory for measuring clinical anxiety: Psychometric properties", Journal of Consulting Psychology, 56, 893-897, 1988. Doi: 10.1037//0022-006x.56.6.893

[18] Ulusoy M, Şahin N, Erkmen H. "Türkish version of the Beck Anxiety İnventory”, J.Cognitive Psychother, 12, 163-172, 1998.

[19] Ghods, K., et al., "The relationship between sleep disorders and quality of life in rotating shift workers at a textile factory", Middle East J. Rehab. Health Stud., 4, 1-7, 2017. doi: 10.5812/mejrh. 12289

[20] Larsen, A.D., et al., "Nightwork, long work weeks, and risk of accidental injuries. A registerbased study". Scandinavian Journal of Work, Environment \& Health, 43, 578-586, 2017. doi:10.5271/sjweh.3668 
[21] Alali, H., et al., "Shift Work and Occupational Accident Absence in Belgium: Findings from the Sixth European Working Condition Survey", Int. J. Environ. Res. Public Health, 15, 1811, 2018. doi:10.3390/ijerph15091811

[22] Medic, G., et al., "Short- and long-term health consequences of sleep disruption", Nature and Science of Sleep, 9, 151-161, 2017. doi:10.2147/NSS.S134864

[23] Salminen, S., "Shift work and extended working hours as risk factors for occupational injury", The Ergonomics Open Journal, 3, 14-18, 2010. doi: 10.2174/1875934301003010014

[24] Papantoniou, K., Devore, E. E., Massa, J., Strohmaier, S., Vetter, C., Yang, L., ... Schernhammer, E. S., "Rotating night shift work and colorectal cancer risk in the nurses' health studies", International Journal of Cancer, 143, 2709-2717, 2018. doi:10.1002/ijc.31655

[25] Lajoie, P., et al., "A cross-sectional study of shift work, sleep quality and cardiometabolic risk in female hospital employees". BMJ Open, 5, e007327, 2015. doi: 10.1136/bmjopen-2014-007327.

[26] Assis, M. A. et al., "Food İntake and Circadian Rhythms in Shiftworkers With A High Workload", Appetite, 40, 175-183, 2003.

[27] Antunes, L.C., et al., "Obesity and shift work: chronobiological aspects", Nutrition Research Reviews, 23, 155-68, 2010. doi: 10.1017/S0954422410000016.

[28] Lin, Y.C., et al., "Persistent rotating shift-work exposure accelerates the development of metabolic syndrome among middle-aged female employees: a five-year follow-up", Chronobiol Int. 26, 740-755, 2009. doi: 10.1080/07420520902929029.

[29] Kazemi, R., et al., "Comparison of Melatonin Profile and Alertness of Firefighters with Different Work Schedules”, Journal of Circadian Rhythms, 16, 1, 2018. doi:10.5334/jcr.155

[30] Halvan1, G.H., et al., "The Relation between shift work, sleepiness, fatigue and accidents in Iranian Industrial Mining Group Workers”, Industrial Health., 47, 134-138, 2009.

[31] Wu, S., et al., "Excessive daytime sleepiness assessed by the Epworth Sleepiness Scale and its association with health-related quality of life: a population-based study in China", BMC Public Health, 12, 849, 2012. doi: 10.1186/1471-2458-12-849.

[32] Swanson, L.M., et al., "Sleep disorders and work performance: findings from the 2008 National Sleep Foundation Sleep in America poll". J Sleep Res, 20, 487-494, 2011. doi: 10.1111/j.13652869.2010.00890.x.

[33] Muthukrishnan, Akila et al. "Association of poor sleep quality with risk factors after coronary artery bypass graft surgery-A prospective cohort study." Journal of vascular nursing: official publication of the Society for Peripheral Vascular Nursing 38, 283-92, 2020. doi:10.1016/j.jvn.2020.02.001

[34] Kalmbach, D. A., et al., "Shift work disorder, depression, and anxiety in the transition to rotating shifts: the role of sleep reactivity". Sleep Med, 16, 1532-1538, 2015.

doi:10.1016/j.sleep.2015.09.007 
[35] Carlisi, C.O., et al., "Sleep-amount differentially affects fear-processing neural circuitry in pediatric anxiety: A preliminary fMRI investigation", Cognitive, Affective, \& Behavioral Neuroscience, 17, 1098-1113, 2017. doi: 10.3758/s13415-017-0535-7.

[36] Teker, A. G., \& Luleci, N. E., "Sleep quality and anxiety level in employees", Northern clinics of Istanbul, 5, 31-36, 2018. doi:10.14744/nci.2017.58855. 